\title{
The Operation Characteristics and open-loop method of 1000/500/220kV Three-level Electromagnetic Loop Network
}

\author{
Qiang $\mathrm{Yu}^{1}{ }^{1}$, , Qing $\mathrm{He}^{1}$, Junchuan $\mathrm{Jia}^{1}$, Jun $\mathrm{Yi}^{1}$ and Jingzhe $\mathrm{Tu}^{1}$ \\ ${ }^{1}$ China Electric Power Research Institute, Beijing 100192,China. \\ ayuqiang2010@epri.sgcc.com.cn
}

Keywords: eletromagnetic loop, Operation Characteristics,open-loop principle; UHV.

\begin{abstract}
During the development of the high-voltage power grid, the emergence of electromagnetic loop in the network is inevitable. To ensure the normal operation of the grid, it needs to deal with the problems brought by electromagnetic loop with scientific methods. In this paper, the impacts of the electromagnetic loop have been discussed from several aspects such as heat stability, transient stability, short-circuit current levels, reactive power and voltage control; an open-loop principle of UHV three-level electromagnetic loop were put forward and its correctness has been proved by the simulation results of the actual grid. The study can provide some suggestions for the new emerging electromagnetic loop problems in the future period of rapid UHV development.
\end{abstract}

\section{Introduction}

With the continuous development of electrical power network scales, high voltage grid are strengthening gradually, the occurrence of a new operation structure that high voltage transmission lines work in parallel with lower voltage ones is inevitable and may affect power system secural operation.

Normally, this new structure, that is called eletromagnetic loop, is only a product in the process of the high voltage power grid formation. The electromagnetic loop can contribute to exerting the equipment's transmission capability, ensuring the reliable power output of power source, improving power supply reliability and so on. However, it also has some negative effects on the normal operation of power system with the increasing of the load and line's transmission power ${ }^{[1-3]}$. It is necessary to open the loop and reduce its operation in the grid ${ }^{[4-6]}$. Especially, under the quickly development of the ultra-high voltage project, it has emerged a $1000 / 500 \mathrm{kV}$ electromagnetic loop in the network, coupled with $500 / 220 \mathrm{kV}$ ones that have already existed but not need to be openned, a new structure of 1000/500/220kV three-stage electromagnetic loop network has been formed, which has a great impact on the normal operation of the power system.

Refering to the problems of the continuous emerging electromagnetic loop in the network during power grid development process, experts and scholars have made a lot of research. For the electromagnetic loop that is not meeting the open-loop conditions, the literature [7-8] proposed reliability and risk assessment approaches and corresponding control method. The literature [9-10] mainly studied the power flow control method of electromagnetic loop under the constraint of power grid security and stability. The literature [11] analyzed the generation mechanism and control measures of the reactive circulation in the electromagnetic loop. In the literature [12], a new conception of power transfer proportion and its affecting factors were proposed after analyzing the open-loop power transfer. Besides, some power transfer attentions were also probed. The literature [13] studied the influence of 750/330 kV electromagnetic loop network in the Northwest grid on the security and stability of the power system, and put forward some measures to ensure the power system stability like strenthening stability devices configuration, developing circuit breaker with greater interrupting capacity and optimizing grid operation mode and structure.

For the electromagnetic loop that is meeting the open-loop conditions, the literature [14] established a fuzzy comprehensive evaluation mode and evaluated the open-loop scheme from the aspects of static security, transient security and economic performance. The literature [15] proposed 
general open-loop steps of $500 / 220 \mathrm{kV}$ electromagnetic loop. The literature [16] studied the $500 / 220 \mathrm{kV}$ electromagnetic loop opening solution according to the situation that three-phase short-circuit current exceeded the normal level. In the literature [17], the general open-loop technical principles in the actual power grid were analyzed.

This article explored the influence of electromagnetic loop on the normal operation of the power grid, put forward an open-loop method of UHV 1000/500/220/kV three-stage electromagnetic loop in the UHV project construction process and provide a reference for further research on the electromagnetic loop in the grid.

\section{Study on the open-loop method for $1000 / 500 / 220 \mathrm{kV}$ electromagnetic loop}

$1000 / 500 / 220 \mathrm{kV}$ three-level electromagnetic loop network is a special configuration, which is a conbination of the $1000 / 500 \mathrm{kV}$ electromagnetic loop and the existed $500 / 220 \mathrm{kV}$ ones in the early stage of the UHV development. Thus, there is not only the problems of 500/220kV electromagnetic loop, but also the new characteristics brought by the $1000 / 500 \mathrm{kV}$ one.

Three 1000/500/220kV electromagnetic loop network will bring more power transfer, higher short-circuit current and more other serious hidden dangers to the safety and stability of power grid operation. When $500 \mathrm{kV}$ or $1000 \mathrm{kV}$ transmission lines lost two circuits simultaneously, a large amount of power transfers to the remaining $500 \mathrm{kV}$ lines, resulting in the $500 \mathrm{kV}$ transmission line power reaches or exceeds the line's heat stability limit. Once the remaining 500kV transmission lines disconnect with the grid, the huge power will transfer to the low voltage $220 \mathrm{kV}$ lines. Due to the lack of adequate reactive power support, the $220 \mathrm{kV}$ voltages of the end bus will decrease significantly, which may even cause the impair to the grid voltage stability. It is imperative to find a method that confirming the timing of the electromagnetic loop network in the environment of UHV power grid. Based on the open-loop principle of $500 / 220 \mathrm{kV}$ electromagnetic loop network, the papaer proposes a $1000 / 500 / 220 \mathrm{kV}$ electromagnetic loop open-loop method, the details are as follows.

Step 1: According to the actual operation scenarios and characteristics of the power grid, confirm the configuration of the electromagnetic loop network.

Step 2: Analyze the impacts of the electromagnetic loop on the UHV grid transmission capacity.

Step 3: compare the effects on the security and stability of the grid before and after the electromagnetic loop disconnetion. And three principles can be refered, which are detailed in the following text.

Step 4: Confirm whether the electromagnetic loop needs to be disconnected by the simulational verification of actual power grid.

The flow diagram of the $1000 / 500 / 220 \mathrm{kV}$ electromagnetic loop opening up method is shown in the figure 1 .

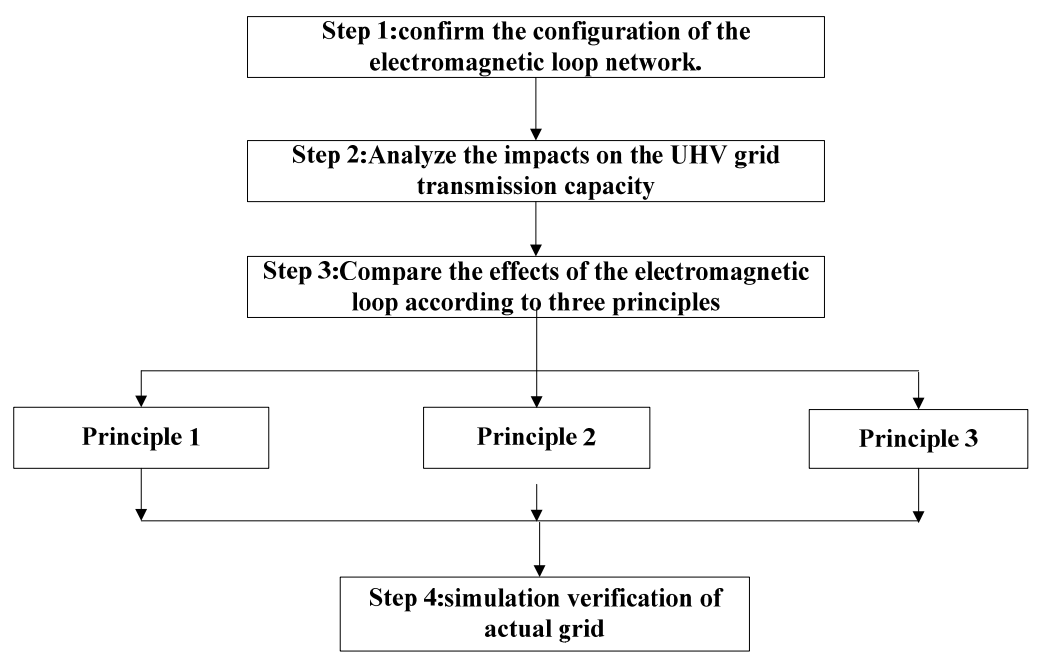

Fig. 1 flow diagram of 1000/500/220kV electromagnetic loop disconnecting method The three principles in the method are detailed as follows: 
Principle 1: compare the effects on the power system operation before and after disconnecting the electromagnetic loop. And evaluate the supporting mesures for the stability of the grid with no electromagnetic loop operating. There are three cases below.

a) The electromagnetic loop operation make an negtive effects on the grid stability and transmission capaity. Besides, the supporting measures after disconnecting the loop are simple and can be easily realized. In the result, the electromagnetic loop can be opened up.

b) The electromagnetic loop operation make an negtive effects on the grid stability and transmission capacity both before and after disconnecting the loop. On the other hand, the supporting measures after disconnecting the loop may be complicated and hardly realized. Thus, it may need deep consideration and comparation on the decision whether the electromagnetic loop should be disconneted.

c) The electromagnetic loop operation make no effects on the grid stability and transmission capacity. However, the supporting measures after disconnecting the loop are complicated. Thus, the disconnecting of the electromagnetic loop makes no sense.

Principle 2: After disconnecting the electromagnetic loop, there are not any negative effects on the power supply reliability.

Principle 3: After disconnecting the electromagnetic loop, the grid operational requirements should comply with the guidelines for power system security and stability.

\section{Simulation analysis}

When Huainan-Huxi UHV AC project put into operation, the new $1000 \mathrm{kV} / 500 \mathrm{kV}$ electromagnetic loop appears. Combined with the existed $500 / 220 \mathrm{kV}$ electromagnetic loop, a more complicated $1000 / 500 / 220 \mathrm{kV}$ three-level loop is under operation in the actual grid. It is the first UHV three-level electromagnetic loop. The figure 3 describes the structure diagram of the grid after the UHV project completed.

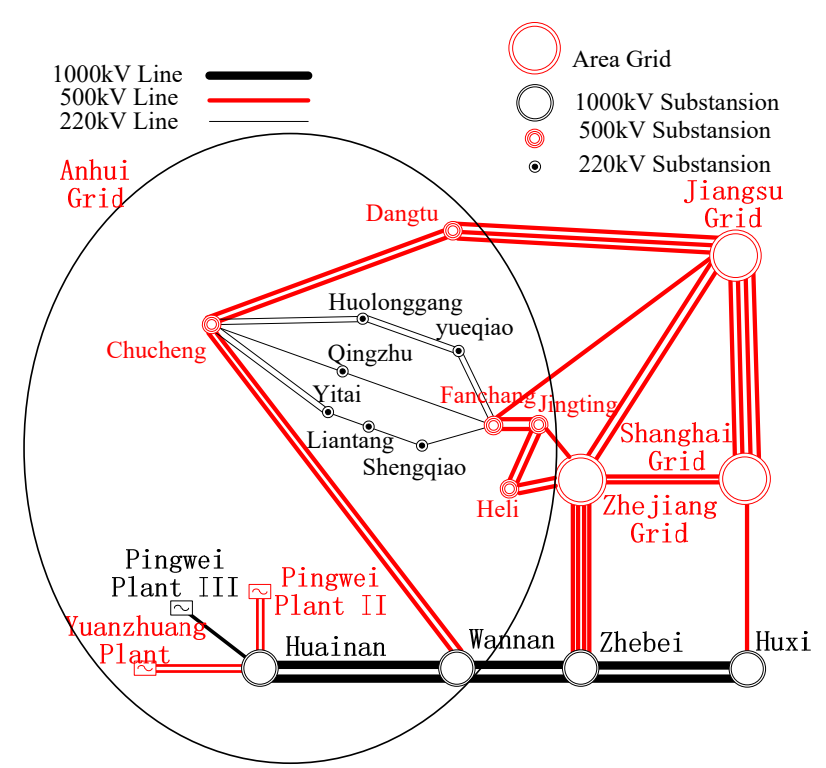

Fig. 2 the structure diagram of the grid

According to the disconnecting method presented above, the detail steps are showed below.

Step 1: confirm the configuration of the electromagnetic loop network. The Huainan-Huxi UHV AC project goes across three provinces that are Anhui, Zhejiang and Shanghai respectively. The $1000 / 500 / 220 \mathrm{kV}$ three-level electromagnetic loop are composited by the transmission lines below.

a) The $1000 \mathrm{kV}$ transmission line from Wannan substation to Zhebei substation.

b) The $500 \mathrm{kV}$ transmission line from Wannan to Chucheng, The $500 \mathrm{kV}$ transmission line from Fanchang to Jiangsu, and the $500 \mathrm{kV}$ transmission line from Jiangsu to Zhejiang.

c) the $220 \mathrm{kV}$ transmission lines between the substation Fanchang and Chucheng.

Step 2: Analyze the effects of the electromagnetic loop on the Huainan-Huxi UHV project transmission capacity. As indicated in the figure, Anhui power delivery section consists of 7 circuits 
$500 \mathrm{kV}$ lines and 2 circuits UHV lines. The power flow through the $500 \mathrm{kV}$ lines are not very big, the Anhui transmission capacity can't be affected when any one of the $500 \mathrm{kV}$ lines confronts 3-phase permanent short circuit to ground. Besides, Huainan-Huxi UHV project is constructed by double-circuit UHV lines and owns the smaller electrical distance than that of the $500 / 220 \mathrm{kV}$ electromagnetic loop between Wannan and Zhebei substation, in the result, when the UHV transmission lines confront 3-phase permanent short circuit to ground, the power can transfer mainly to the other UHV line, which makes little effect to the $550 / 220 \mathrm{kV}$ lines. After the simulation, about $91.8 \%$ of the power flowing through the double circuit UHV lines transfers to the other UHV lines and only $9.2 \%$ power transfers to the lower-grade transmission lines. The UHV lines transmission capacity can't be affected by the electromagnetic loop.

Step 3: Compare the effects on the security and stability before and after the loop disconnected.

a) Compare the short circuit current level. The short circuit current levels before and after the loop disconnected are listed in the table 1. From the table 1, it can be concluded that the short circuit current levels before and after the loop disconnected are both less than the level of $60 \mathrm{kV}$. Thus, the short circuit current level is not the main factor that decides whether the loop should be disconnected.

Table 1 Short Circuit Current Level

\begin{tabular}{cccc}
\hline Numble & $\begin{array}{c}\text { Substation } \\
\text { Name }\end{array}$ & $\begin{array}{c}\text { Short Circuit Cureent Level(kA) } \\
\text { (Before disconencted) }\end{array}$ & $\begin{array}{c}\text { Short Circuit Cureent Level(kA) } \\
\text { (After disconencted) }\end{array}$ \\
\hline 1 & Wannan & 57.67 & 57.19 \\
2 & Chucheng & 48.431 & 44.98 \\
3 & Dangtu & 42.590 & 40.88 \\
4 & Heli & 28.739 & 18.34 \\
5 & Jingting & 27.732 & 18.86 \\
6 & Zhebei & 51.091 & 50.19 \\
\hline
\end{tabular}

b) Compare the effects on the power system stabilities. According to the power system stability analysis, the system can maintain stable operation after confronting 3-phase short circuit, DC power block and other single fault. The figure 4 shows the system generators' angle traces after the grid disturbances.

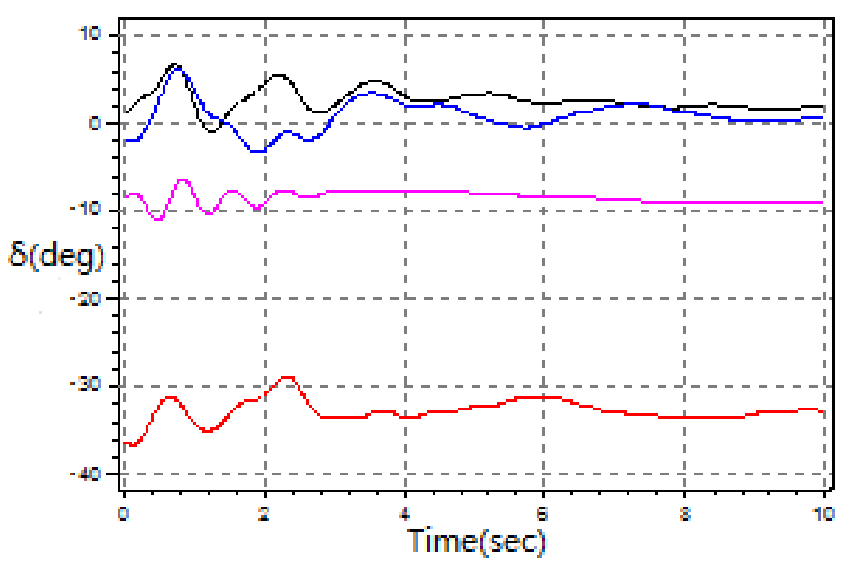

Fig. 3 generator angle traces after the system disturbance

c) Compare the power supply reliability and the related disconnection support measures. Under the electromagnetic loop network operation mode, when the UHV lines between Anhui and Zhejiang lost both the two circuits, the $87.6 \%$ of the power flowing through the UHV lines may transfer to the $500 \mathrm{kV}$ lines and only $12.4 \%$ power transfer to Chucheng substation that can delivery through $220 \mathrm{kV}$ lines. Thus, the $500 \mathrm{kV}$ lines may easily be overloaded and it needs to trip a lot of generators to guarantee the grid stability. 
Once the $220 \mathrm{kV}$ lines disconnected, it may aggravate the $500 \mathrm{kV}$ overload problem. Besides, when the $220 \mathrm{kV}$ lines disconnected, some $220 \mathrm{kV}$ substations may become to the terminal substation. The power supply reliability may become worse.

In the conclusion, it is not necessary to disconnect the electromagnetic loop.

\section{Summary}

Electromagnetic loop network is an inevitable production in the process of power grid development. However, the electromagnetic loop network often has a great impact on the power grid security and stability and usually need to be disconnected. Based on the analysis of the two-level electromagnetic loop network influence on the normal operation of the power grid, the paper proposed a new disconnection method for $1000 / 500 / 220 \mathrm{kV}$ three-level electromagnetic loop. The method can make an important sense for the power system stable operation during the transition of the UHV development.

\section{References}

[1] LIN Weifang, SUN Huadong, TANG Yong, BU Guangquan, YIN Yonghua. Analysis and Lessons of the Blackout in Brazil Power Grid on November 10,2009. Automation of Electric Power System. 2010, 34(7):1-5.

[2] CHENG Haihui. Analysis of the operation with 500/220kV electromagnetic loop disconnected. Jiangsu Electric Egineering. 2005, 24(5):38-40.

[3] TANG Siqing, ZHANG Mi, LI Jianshe, WU Xiaochen, JIANG Kun, SHU Shuangyan. Review of "9-26" Blackout in Hainan Grid: Causes and Recommendations. Southern Power System Technology Research. 2006,2(1):13-18.

[4] HOU Chunqing, Zheng Huiping. Research on Operation Mode of 500/220kV Electromagnetic Loop Network in Shanxi Central and South Power Grid. Power System Technology. 2005, 29(10): $80-84$

[5] LIU Mingsong, ZHANG Jian, ZANG Wenchao. Problems and Countermeasures for Operation and Control of Weak Electromagnetic loops. Automation of Electric Power System. 2014, 38(4): $109-114$

[6] ZHANG Zuping, FAN Mingtian, Zhou Limei. Research of Breaking up Electromagnetic Ring in Urban Power Network. Power System Technology. 2008, 32(19): 42-44.

[7] REN Zheng, CHEN Biyun. Improved Evaluation Model for Complex Transmission Networks. Automation of Electric Power System. 2005, 29(5): 26-30.

[8] YANG Yihan, AI Lin, JIANG Tong, etc. Risk Assessment and Control of Electromagnetically Coupled Power loop Based on Benefit Risk Function Improved Evaluation Model for Complex Transmission Networks. Power System Technology. 2009, 33(7): 65-70.

[9] Marinakis A, Glavic M, Van Cutsem T. Minimal reduction of un scheduled flows for security restoration: application to phase shifter control[J]. IEEE Trans on Power Systems, 2010, 25(1): 506-515.

[10] Granelli G, Montagna M, Zanellini F, et al. A genetic algorithm-based procedure to optimize system topology against parallel flows[J]. IEEE Trans on Power Systems, 2006, 21(1): 333-340.

[11] CHENG Lin, LIU Wenying, WANG Weizhou, etc. Analysis and Control of Reactive Circular Power Flow in Looped Electromagnetically Coupled Power Networks. Power System Technology. 2007, 31(8): 64-67. 
[12] ZHOU Zhuan, YAO Xiuping, WANG Weiqing, etc. Research and analysis of power transfer based on multiple electromagnetic looped network. Power System Protection and Control. 2013, 41(22): 134-140.

[13] PAN Wei, LIU Wenying, YANG Yihan, etc. Research on Operating Modes of $750 \mathrm{kV}$ Northwest China Power Grid Electro-Magnetically Coupled with 330 kV Power Grid. Power System Technology. 2007, 31(15): 34-38.

[14] YE Hua, LIU Yutian, NIU Xinsheng. Fuzzy comprehensive evaluation of opening schemes for 500 kV- 220 kV electromagnetic loop. Electric Power Automation Equipment. 2006, 26(7): 1-5.

[15] KONG Tao, WANG Hongtao, LIU Yutian, etc. On opening 500kV-220kV electromagnetic loop circuit. Electric Power Automation Equipment. 2003, 23(12): 13-16.

[16] LIU Nan, TANG Xiaojun, ZHANG Wenchao, etc. Study on Electromagnetic Ring Opening in Henan Province under Ultra-high Voltage Power Grid. Power System Protection and Control. 2011, 39(2): 131-136.

[17] ZHOU Limei, FAN Mingtian, ZHANG Zuping, etc. LIU Yutian, NIU Xinsheng. Analysis on Breaking up Electromagnetic Ring in Hefei Urban Power Network. Power System Technology. 2008, 32(20): 73-76. 